\title{
An MTSS Based Underground Coal Mining Simulation Model
}

\author{
Victor Okolnishnikov \\ Institute of Computational Technologies \\ Siberian Branch of the Russian Academy of Sciences \\ Novosibirsk, Russia \\ okoln@mail.ru
}

\begin{abstract}
In the frames of simulation system, a specialized library of simulating models of mining equipment and coal seam (MTSS) was implemented. Using the specialized simulating model library of technological mining equipment an integrated model for technological processes of underground coal mining in stoping face was developed. The main goal of simulation for coal mining technological processes in stoping face is the evaluation of productivity of a cutter-loader depending on different factors like the technical parameters of the cutter-loader, size of the longwall face, geophysical state of the coal seam.
\end{abstract}

Keywords-coal mining; simulation system; visual interactive simulation; longwall mining system

\section{INTRODUCTION}

Many coal mines face problems while making decisions to increase productivity, improve coal production planning, use new mining equipment and new perspective technologies for coal mining. The most suitable way to solve these problems is simulation. A large number of publications on the use of simulation to support decision making on the design, development and optimization of coal mines testifies the importance of these problems [1-8]. To solve these problems the simulation system MTSS [9] was developed. It is a visual interactive and process-oriented discrete simulation system intended to develop and execute the technological processes of models. A distinguishing feature of the simulation system is its orientation towards users who are experts in a particular subject area (process engineers, mining engineers) but do not have experience in usage of universal simulation systems. Fast model development is carried out due to the visual-interactive interface and specialized model libraries of technological equipment for specific subject areas. The simulation system MTSS provides the user with the following options: visually interactive model construction with a graphical editor, setting model parameters, various modes of model execution, 2D and $3 \mathrm{D}$ model visualization. MTSS uses $2 \mathrm{D}$ as a graphical editor and 2D, 3D visualization of model execution. To simulate the technological processes in coal mines in MTSS the specialized libraries of technological equipment for such mine subsystems as an underground conveyor network, a pumping subsystem, and a power supply subsystem were developed. With the use of the specialized libraries a number of models of these subsystems for underground coal mines in Kuznetsk Coal Basin (Russia, Western Siberia) were created [10].

In this article a new specialized library of models of mining equipment in the stoping face is considered. The second section provides a mathematical model of the technological process of coal mining in the stoping face. The third section describes the simulation model of the technological process of coal mining in the stoping face developed using the new specialized library of models and the results of its implementation.

\section{THE MATHEMATICAL MODEL OF PRODUCTIVITY OF THE CUTTER-LOADER}

The theoretical advance speed of a cutter-loader is $[11,12]$ :

$V=\frac{30 N \eta n_{1} K_{1}}{f P \cos \alpha \pm P \sin \alpha+S D n_{2} K_{2} K_{3} K_{4} K_{5} K_{6}}$

where

$V$ — the speed of the cutter-loader,

$N$ - the power of the effector motor,

$\eta$ - the efficiency of the effector reduction gearing,

$n_{1}$ - the cutting tools in the cutting line,

$K_{1}$ - the coefficient of the horsepower input to cutterloader travel,

$f$ - the cutter-loader and transporter friction coefficient,

$P$ — the cutter-loader weight,

$\alpha$ - the angle of inclination of the cutter-loader.

"Plus" and "minus" in front of the cutter-loader weight specify the cutter-loader movement up and down the longwall, respectively.

$S$ - the weighted average of the coal cutting resistance,

$D$ - the diameter of the augers,

$n_{2}$ - the cutting tools that synchronously cut the face,

$K_{2}$ - the coefficient of squeeze which takes into account the cutting force decrease due to the ground pressure. 
$K_{3}, K_{4}, K_{5}, K_{6}$ are the coefficients for the cutting angle, the cutting tool width, the cutting tool dulling and the cutting tool shape, respectively.

Among the above mentioned parameters the coal cutting resistance $S$ influences the motion rate the most. The coal cutting resistance is considered to be invariable in a certain vast area and is defined by data obtained while drilling the geological prospecting well with (2)

$$
S_{1}=\frac{k\left(m_{c} f_{c}+m_{r} f_{r}\right)}{m_{c}+m_{r}}
$$

where

$m_{c}, m_{r}$ - the coal mass and the rock mass respectively,

$f_{c}, f_{r}$ - the coal hardness and the interbed rock hardness respectively,

$k$ - a certain coefficient.

In the case of several geological prospecting wells $S$ is calculated with the inverse distance weighting method according to (3).

$$
S(X, Y)=\left\{\begin{array}{l}
\frac{\sum_{i=1}^{n} d_{i}^{-2} S_{i}}{\sum_{i=1}^{n} d_{i}^{-2}}, \text { if } d_{i} \neq 0 \\
S_{i}, \text { if } d_{i}=0
\end{array}\right.
$$

where

$n$ - the number of wells nearest to stoping face that are taken into account while calculating,

$S_{i}$ - the coal cutting resistance in i-th well calculated with (2),

$d_{i}$ - the distance between the i-th well and the mining face with current position $(X, Y)$, calculated with (4)

$$
d_{i}=\sqrt{\left(X-x_{i}\right)^{2}+\left(Y-y_{i}\right)^{2}}
$$

where $\left(x_{i}, y_{i}\right)$ - the coordinates of the $\mathrm{i}^{\text {th }}$ well.

While one-way operating of the cutter-loader the time of one way is:

$$
\begin{aligned}
& T_{\text {one way }}=T_{1}+T_{\text {scr }}+T_{\text {end one cut }} \\
& =\frac{L}{V_{1}}+\frac{L}{V_{\text {scr }}}+T_{\text {end one cut }}
\end{aligned}
$$

where

$L$ - the length of the longwall face,

$V_{I}$ - the speed of the cutter-loader movement up the longwall determined by (1),

$V_{s c r}$ - the speed of the cutter-loader movement when scraping operation is performing,

$T_{\text {end one cut }}$ - the time of the cutter-loader at the end of the longwall face by one-way operating.

While shuttle operating of the cutter-loader the time of one cycle is:

$$
T_{\text {shuttle }}=T_{1}+T_{2}+2 T_{\text {end }}=\frac{L}{V_{1}}+\frac{L}{V_{2}}+2 T_{\text {end }}
$$

where

$L$ - the length of the longwall face,

$V_{1}, V_{2}$ - the speeds of the cutter-loader movement up and down the longwall determined by (1), respectively,

$T_{\text {end }}$ - the time of the cutter-loader at the end of the longwall face by shuttle operating.

While one-way operating of the cutter-loader the productivity of the cutter-loader per time $T_{\text {work }}$ is :

$$
A_{\text {one way }}=\frac{\gamma m r L T_{\text {work }}}{T_{\text {one way }}}
$$

where

$\gamma$ - the average mean density of the rock mass,

$m$ - the working-bed height,

$r$ - the cutter-loader cut width.

Substituting $V_{l}$ from (1) into (5) and $T_{\text {one way }}$ from (5) into (7) we get:

$$
A_{\text {one way }}=\frac{\gamma m r T_{\text {work }}}{\frac{f P \cos \alpha+P \sin \alpha+S D n_{2} K_{2} K_{3} K_{4} K_{5} K_{6}}{30 N \eta n_{1} K_{1}}+\frac{1}{V_{s e r}}+\frac{T_{\text {end onecut }}}{L}}
$$

While shuttle operating of the cutter-loader the productivity of the cutter-loader per time $T_{\text {work }}$ is:

$$
A_{\text {shuttle }}=\frac{2 \gamma m r L T_{\text {work }}}{T_{\text {shuttle }}}
$$

Substituting $V_{1}, V_{2}$ from (1) into (6) and $T_{\text {shuttle }}$ from (6) into (9) we get:

$$
A_{\text {shutle }}=\frac{\gamma m r T_{\text {work }}}{\frac{f P \cos \alpha+S D n_{2} K_{2} K_{3} K_{4} K_{5} K_{6}}{30 N \eta n_{1} K_{1}}+\frac{T_{\text {end }}}{L}}
$$

\section{INTEGRATED SIMULATING MODEL OF STOPING FACE OPERATIONS}

In the frames of simulation system MTSS, a specialized library of simulating models of mining equipment (a conveyor, a cutter-loader, a self-moving roof support etc.) used in coal mining in stoping face was implemented. Using the specialized library of simulating models of mining equipment an integrated model for technological processes of underground coal mining in stoping face was developed. The integrated model involves the following interactive models:

- a coal seam model,

- a cutter-loader model moving up and down the longwall face,

- a model of a self-moving roof support,

- a model of a flight conveyor. 
All parameters of the mine equipment models correlate with the parameters of the actual mine equipment operating at one of the coal mine in in Kuznetsk Coal Basin. The goals of the simulation for coal mining technological processes in stoping face are:

- the evaluation of productivity of a cutter-loader depending on different factors including the variety of geophysical conditions of the coal seam,

- the input data acquisition (input coal stream) for operating of the belt conveyor network model of the coal mine.

Generally, in the stoping face the following factors influence the productivity of the cutter-loader:

- the geophysical state of the coal seam,

- the advance speed of the cutter-loader,

- the technical characteristics of the cutter-loader,

- the delays at the end of the longwall face,

- the delays associated with the movement of the roof support,

- the delays associated with the flight conveyor,

- the delays associated with the belt conveyor,

- the delays associated with the increase of methane release,

- the delays associated with equipment failures,

- regulation conditions and maintenance etc.

In this paper, the influence of the first six factors of the cutter-loader productivity was studied. Since the main factor influencing the cutter-loader productivity is the state of the coal seam (the coal cutting resistance) which restricts the advance speed of the cutter-loader, the subject of the research is the detailed simulating of one-way operating and shuttle operating of the cutter-loader together with roof supports movement depending on the geophysical state of the coal seam. Under these conditions the top speed and the cutter-loader productivity were calculated with (1) and (7). Figure 1 shows the coal seam model with two geological prospecting wells. Figure 2 shows the integrated model of underground coal mining technological processes in stoping face carried out with simulation system MTSS. The coal seam with two geological prospecting wells is painted over. The areas with reduced resistance are painted in a lighter tone. The belt conveyor and power lines are designated in the main window. The equipment parameters and operation modes can be set interactively in the parameters window. The control buttons are entered in the main window: to start the cutter-loader; to stop the cutterloader. With the developed simulation model of the technological process of underground coal mining in the stoping face a series of experiments was performed. For oneway and shuttle operations the average productivity of the cutter-loader was calculated, depending on the length of the longwall face. All experiments were carried out under equal conditions of the passage of the cutter-loader for a certain depth into the coal seam.

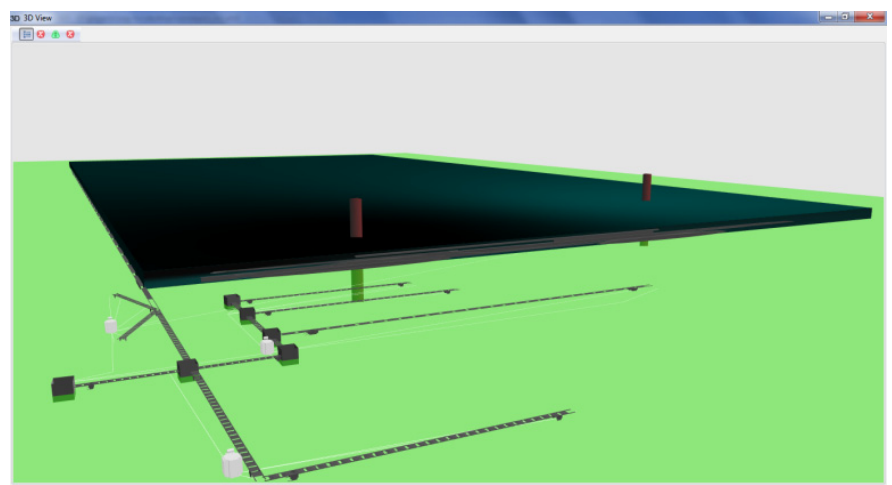

Fig. 1. The 3D coal seam model with two geological prospecting wells.

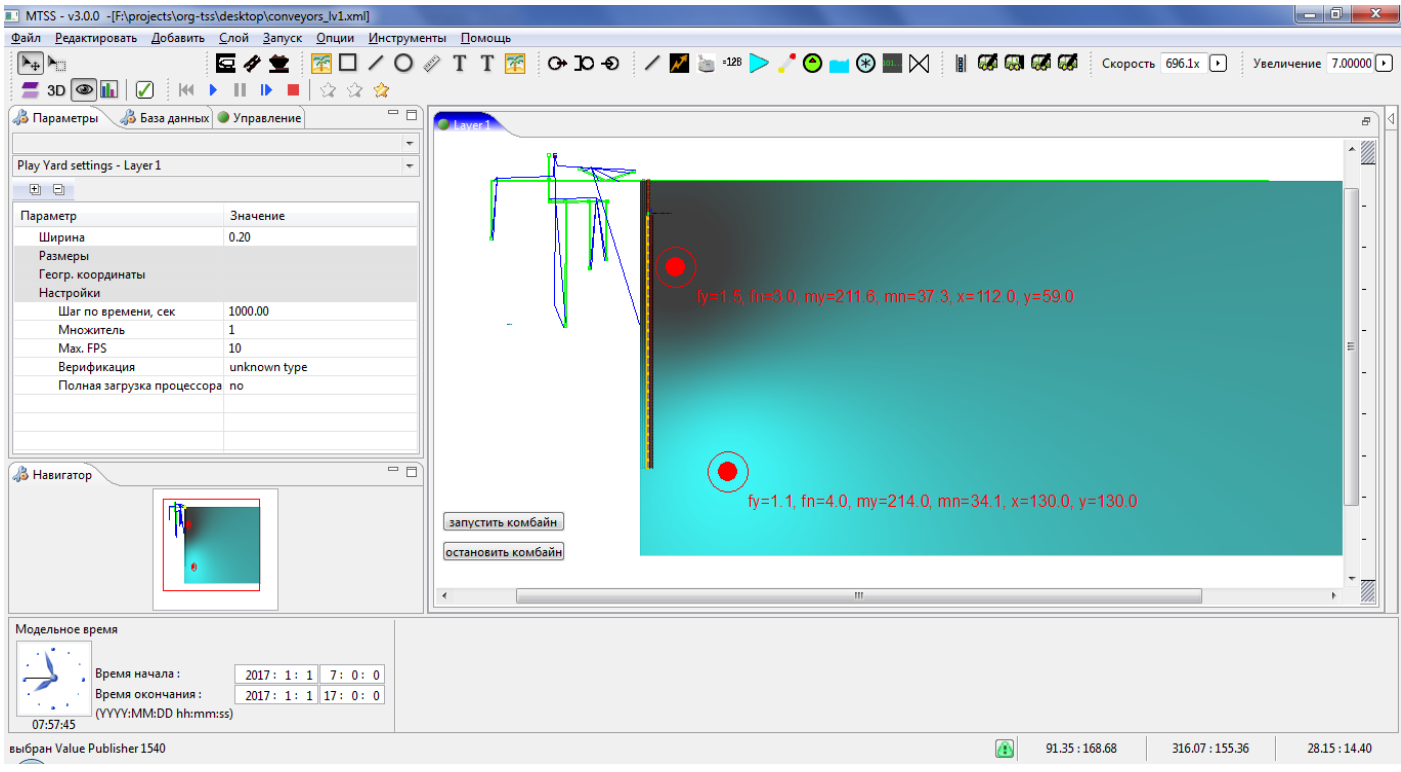

Fig. 2. The main window of the stoping face model. 
The obtained results are presented in the form of graphs in Figure 3. The obtained results allow us to conclude the following:

- The shuttle operation of coal mining in the stoping face is more productive in comparison with the one-way operation.

- Increasing the length of the longwall face, beginning from a certain value, does not significantly affect the increase in the productivity of the cutter-loader.

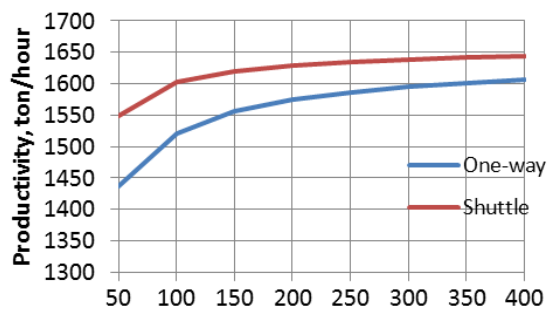

Fig. 3. The dependence of the productivity of the cutter-loader on the length of longwall face.

\section{CONCLUSION}

The extension of the considered simulation model of the stoping face operation is assumed to be carried out in the future. Models of aerogasdynamics of methane-air flow in a long stope and models of a belt conveyors subsystem, a ventilating subsystem and a power supply subsystem of the coal mine will be additionally included into the integrated model of the stoping face operation. The MTSS simulation system can be used not only for simulation of the existing coal mining technologies, but also for simulation of perspective robotized technologies and staffless coal mining technologies.

\section{ACKNOWLEDGEMENT}

This research was partially financially supported by the Russian Foundation for Basic Research (project 16-07-01179).

\section{REFERENCES}

[1] A. Salama, J. Greberg, H. Schunnesson, "The use of discrete event simulation for underground haulage mining equipment selection", International Journal of Mining and Mineral Engineering, Vol. 5, No. 3, pp. 256-271, 2014

[2] M. Fioroni, L. Santos, L. Franzese, I. Santana, G. Telles, J. Seixas, B. Penna, G. Alkmim, "Logistic Evaluation of an Underground mine Using Simulation", 2014 Winter Simulation Conference, Savannah, GA, USA, pp. $1855-1865,2014$

[3] T. N. Michalakopoulos, C. P. Roumpos, Michael J. Galetakis, G. N. Panagiotou, "Discrete-Event Simulation of Continuous Mining Systems in Multi-layer Lignite Deposits", Lecture Notes in Production Engineering, Proceedings of the 12th International Symposium Continuous Surface Mining, Aachen, Germany, pp. 225-239, Springer, 2015

[4] P. Gospodarczyk, "Modeling and Simulation of Coal Loading by Cutting Drum in Flat Seams", Archives of Mining Sciences, Vol. 61, No. 2, pp. 385-379, 2016

[5] T. Kara, M. Cengiz Savas, "Design and Simulation of a Decentralized Railway Traffic Control System", Engineering, Technology \& Applied Science Research, Vol. 6, No. 2, pp. 945-951, 2016

[6] M. Ben Ayed, L. Zouari, M. Abid, "Software In the Loop Simulation for Robot Manipulators", Engineering, Technology \& Applied Science Research, Vol. 7, No. 5, pp. 2017-2021, 2017
[7] Y. Gao, D. Liu, X. Zhang, M. He, "Analysis and Optimization of Entry Stability in Underground Longwall Mining", Sustainability, Vol. 9, No. 11, 2079, 2017

[8] R. Snopkowski, A. Napieraj, M. Sukiennik, "Method of the Assessment of the Influence of Longwall Effective Working Time Onto Obtained Mining Output", Archives of Mining Sciences, Vol. 61, No. 4, pp. 967977, 2017

[9] V. V. Okolnishnikov, S. V. Rudometov, "A System for Computer Simulation of Technological Processes", St. Petersburg State Polytechnic University Journal. Computer Science. Telecommunications and Control Systems, Vol. 181, No. 1, pp. 62-68, 2014

[10] V. Okolnishnikov, S. Rudometov, S. Zhuravlev, "Simulating the Various Subsystems of a Coal Mine", Engineering, Technology \& Applied Science Research, Vol. 6, No. 3, pp. 993-999, 2016

[11] A. A. Ordin, A. A. Metel'kov, "Optimization of the fully-mechanized stoping face length and efficiency in a coal mine", Journal of Mining Science, Vol. 49, No. 2, pp. 254-264, 2013

[12] A. A. Ordin, A. A. Metel'kov, "Analysis of longwall face output in screw-type cutter-loader-and-scraper conveyor system in underground mining of flat-lying coal beds", Journal of Mining Science, Vol. 51, No. 6, pp. 1173-1179, 2015 